compare abundances of cell clusters, the association model Prediction Analysis for Microarrays (PAMR) was applied with a minimum cluster size of $2.2 \%, 5$ cross-validation folds and a false discovery rate of $1 \%$.

Results: Conventional biaxial gating showed that there were large differences in the proportions of both IFN $\gamma^{+}$CD4 T cells (1-15\%) and IL-17A $A^{+}$CD4 T cells $(0-9 \%)$ within and between RA and HC. The proportion of IFN $\gamma^{+}$CD4 T cells (Th1) did not correlate with that of IL-17A + T cells (Th17), leading to the generation of 4 immunophenotypes: "Th1", "Th17", "double-hi", and "low", determined by cytokine expression.

Using CITRUS we identified 3 clusters of cells which differed significantly in abundance between $\mathrm{HC}$ and RA. Cluster 1 was $\mathrm{CD} 4^{+} \mathrm{CD} 38^{+}$, had characteristics of regulatory $\mathrm{T}$ cells and was more abundant in $\mathrm{HC}$. Cluster 2 was $\mathrm{CD} 28^{\text {low }} \mathrm{CD}^{+}$ expressing perforin and Tbet, and cluster 3 a $\mathrm{CD} 127^{\text {high }} \mathrm{CCR} 6^{+}$population, both of which were more abundant in RA.

Conclusions: Cytokine expression of ex vivo stimulated T cells from RA and HC is highly variable and can be detected using mass cytometry. Cytokine signatures of this kind may be informative when predicting treatment response.

CITRUS identified 3 cell clusters which may have been missed using conventional methods of analysis. Importantly, CITRUS allowed inspection of the phenotype of each cluster.

Our next step is to compare RA responders to non-responders using the methods described. The function of these clusters will be further investigated by cell isolation with fluorescence-activated cell sorting (FACS) and may go some way in predicting treatment response. Finally we recommend the use of both automated clustering algorithms alongside conventional gating methods when analysing high-dimensional data.

Disclosure of Interest: None declared

DOI: 10.1136/annrheumdis-2017-eular.2067

\section{OP0095 PREDICTION OF CONNECTIVE TISSUE DISEASE IN AN AT-RISK COHORT USING A NOVEL INTERFERON STIMULATED GENE EXPRESSION SCORE}

M.Y. Md Yusof, Y. El-Sherbiny, A. Psarras, E. Hensor, A. Alase, A. Mohamed, M. Wittmann, P. Emery, E.M. Vital. Leeds Institute of Rheumatic and Musculoskeletal Medicine, University of Leeds, Leeds, United Kingdom

Background: A period of ANA positivity and other immune dysregulation precedes connective tissue disease, providing a potential opportunity for disease prevention. Type I interferons (IFN-I) play a role in pathogenesis but their role in disease initiation is unclear.

Objectives: To develop biomarkers of progression to systemic autoimmunity, with a view to enabling early intervention for disease prevention.

Methods: A prospective observational study was conducted in 125 patients At Risk of CTD defined by (i) ANA; (ii) $\leq 1$ clinical SLE criteria; (iii) symptom duration $<12$ months and (iv) treatment-naïve. Progression was defined by meeting 2012 ACR/SLICC SLE, 2016 ACR/EULAR Primary Sjogren's, or other diagnostic criteria. Expression of 30 selected="selected" ISGs was measured using Taqman. Factor analysis was used to reduce the gene expression data to a limited set of factors, which were compared between patient groups using Mann Whitney $U$ Test. Two factor scores explained $80 \%$ of the data variance; "Score A" (composed of IFN- $\alpha$ responsive genes) and "Score B" (genes responsive to IFN- $\alpha$ and $\gamma$ ). 95 healthy controls and 107 SLE patients were used as negative and positive controls. Results: 82 patients with 1-year follow-up data were studied. 71 were female with mean age $48 \pm 15$ years. $16(20 \%)$ patients progressed to CTD (SLE=12, Sjogren's=4) in the following 12 months. At baseline, only IFN Score A was increased in both At Risk-CTD and SLE vs healthy controls; $p<0.001$. IFN Score $B$ was only increased in true established SLE.

In At-Risk patients, IFN Score B was low in patients who did not progress and increased in those who did progress; $p=0.004$. However, there was no difference in IFN Score A between these two groups; $p=0.252$ (Figure 1). Although complement levels and lymphocyte counts were lower in SLE, these were not different between the At-Risk progression and non-progression groups. Anti-dsDNA titres were higher in SLE but not different between the progression groups; all $p>0.10$.
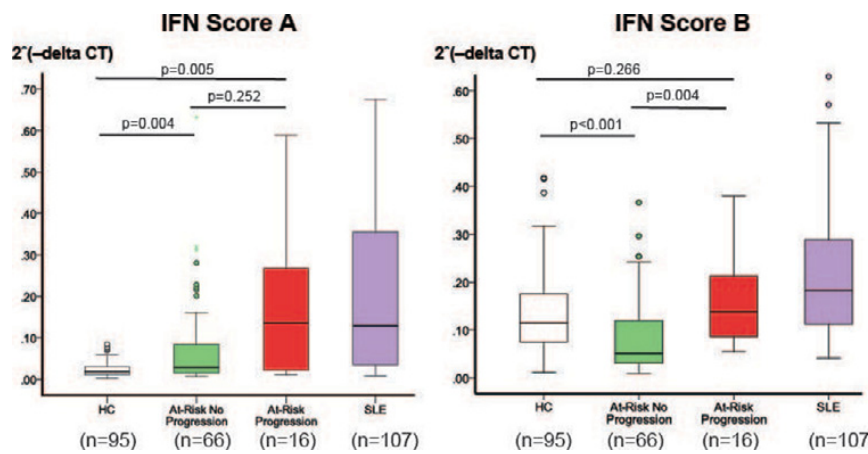

Conclusions: A novel ISG score predicts progression from ANA+ to clinical autoimmune disease. This may allow early intervention to prevent CTD. Analysis of other clinical, immunological and imaging biomarkers are in progress as well as a validation cohort.

Disclosure of Interest: M. Y. Md Yusof: None declared, Y. El-Sherbiny Grant/research support from: AstraZeneca, A. Psarras: None declared, E. Hensor: None declared, A. Alase: None declared, A. Mohamed: None declared, M. Wittmann: None declared, P. Emery Grant/research support from: AstraZeneca, E. Vital Grant/research support from: AstraZeneca DOI: 10.1136/annrheumdis-2017-eular.6925

\section{OP0096 INTERFERON SIGNATURE IN SYSTEMIC SCLEROSIS LUNG MICROVASCULAR ENDOTHELIAL CELLS}

F.A. Mendoza ${ }^{1}$, S. Piera-Velazquez ${ }^{2}$, P. Wermuth ${ }^{2}$, S. Addya ${ }^{3}$,

C. Feghali-Bostwick ${ }^{4}$, S.A. Jimenez ${ }^{2}$. 'Division of Rheumatology and

Scleroderma Center; ${ }^{2}$ Jefferson Institute of Molecular Medicine and Scleroderma Center; ${ }^{3}$ Kimmel Cancer Center, Thomas Jefferson University, Philadelphia;

${ }^{4}$ Division of Rheumatology \& Immunology, Medical University of South Carolina, Charleston, United States

Background: Systemic Sclerosis (SSc) is characterized by severe fibroproliferative vasculopathy, exaggerated deposition of extracellular matrix molecules (ECM) in skin and multiple internal organs, and alterations of humoral, cellular and innate immunity. Vascular changes are responsible for the earliest and most severe SSc clinical manifestations, however, the mechanisms responsible have not been elucidated.

Objectives: The goal of this study was to analyze the gene expression differences between normal and SSc lung microvascular endothelial cells (EC) to improve the understanding of SSc vasculopathy pathophysiology.

Methods: Pulmonary microvascular EC were isolated employing immunomagnetic procedures from lungs from patients with SSc undergoing lung transplantation. Control pulmonary microvascular EC were isolated from autopsies of individuals who died from non-pulmonary causes. Following isolation, microarrays were performed in EC from each group. Expression of genes with the highest differential expression was validated with RT-PCR and Western blots.

Results: Interferon-stimulated genes (ISGs) including IFI44L, IFI44, IFI6, IFIH1, IFIT1 displayed the highest differential expression; being overexpressed in EC obtained from the three SSc donors (Figure 1). Other genes such as those encoding ECM production related proteins, genes associated with posttranslational methylation, and genes for numerous chemokines and cytokines were also differentially overexpressed in SSc EC. Increased gene expression and increased protein levels of selected ISGs were confirmed by Western blots.

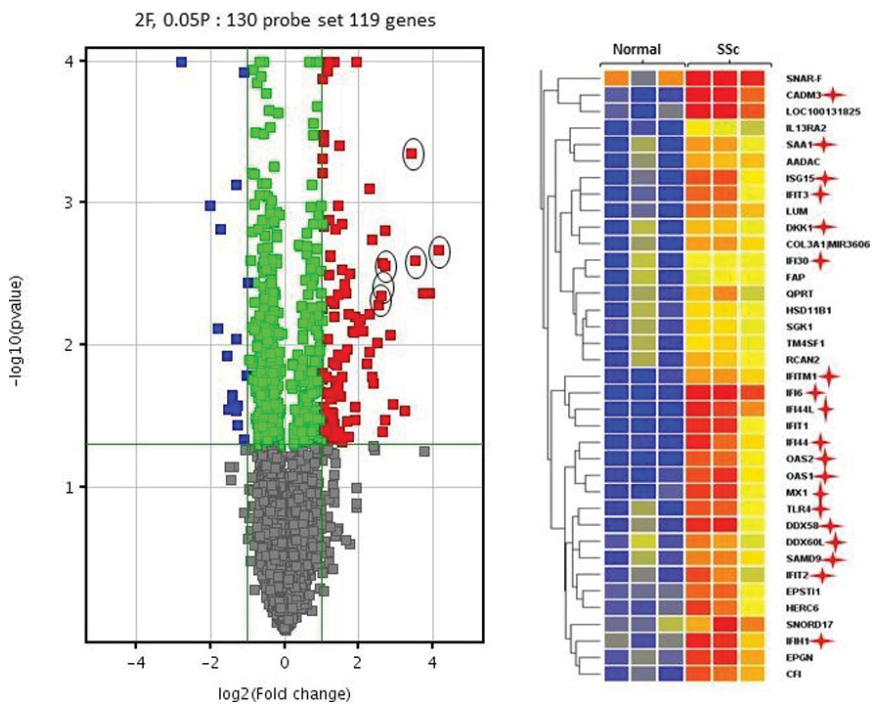

Figure 1. A: Volcano Plot showing differentially expressed transcripts with 2 fold or greater difference $(p<0.05)$ in expression between SSc and normal control microvascular ECs (130 transcripts corresponding to119 genes). Selected ISGs are encircled (IFI-6, IFIT1, IFI-44,IFI44L, IFIT3, OAS-1) B: Detail of the resulting heat map of a dendrogram (hierarchically clustered) reveals groups of genes with high expression levels (red squares), low expression levels (blue squares) or background expression levels (yellow squares). Interferon related genes are marked with a red star.

Conclusions: Numerous ISGs are differentially overexpressed in SSc pulmonary microvascular EC in comparison with normal control EC. These results suggest that events leading to an interferon response in these cells may play a role in the pathogenesis of SSc lung vasculopathy.

References:

[1] Kahaleh B. Vascular Disease in Scleroderma: Mechanisms of Vascular Injury. Rheumatic Disease Clinics of North America 2008; 34(1):57-71.

[2] Trojanowska M. Cellular and molecular aspects of vascular dysfunction in systemic sclerosis. Nat Rev Rheumatol 2010; 6(8):453-60. 
[3] Matucci-Cerinic M, Kahaleh B, Wigley FM. Review: evidence that systemic sclerosis is a vascular disease. Arthritis and rheumatism 2013;65(8):1953-62.

[4] Pattanaik D, Brown M, Postlethwaite BC, Postlethwaite AE. Pathogenesis of Systemic Sclerosis. Frontiers in immunology 2015; 6:272.

Disclosure of Interest: None declared

DOI: 10.1136/annrheumdis-2017-eular.3739

\section{THURSDAY, 15 JUNE 2017 Cytokines and chemokines}

\section{OP0097 SYSTEMIC IFN TYPE I AND TYPE II SIGNATURES IN PRIMARY SJÖGREN'S SYNDROME REVEAL DIFFERENCES IN DISEASE SEVERITY}

I. Bodewes ${ }^{1}$, S. Al-Ali ${ }^{2,3}$, C.G. van Helden ${ }^{1}$, N.I. Maria ${ }^{1}$, J. Tarn ${ }^{2}$, D. Lendrem ${ }^{2}$, M.W. Schreurs ${ }^{1}$, E.C. Steenwijk ${ }^{1}$, P.L.A. van Daele ${ }^{1,4}$, T. Both $^{4}$, S. Bowman ${ }^{5}$ B. Griffiths ${ }^{6}$, W.-F. Ng ${ }^{2,7}$, M.A. Versnel ${ }^{1} .{ }^{1} /$ mmunology, Erasmus MC, Rotterdam, Netherlands; ${ }^{2}$ Musculoskeletal Research group, Newcastle University, Newcastle upon Tyne, United Kingdom; ${ }^{3}$ University of Basrah, Basrah, Iraq; ${ }^{4}$ Internal Medicine, Erasmus MC, Rotterdam, Netherlands; ${ }^{5}$ Rheumatology, University Hospital Birmingham, Birmingham; ${ }^{6}$ Newcastle upon Tyne Hospitals NHS Foundation Trust; ${ }^{7}$ National Institute for Health Research, Newcastle Biomedical Research Centre, Newcastle upon Tyne, United Kingdom

Background: Local and systemic activation of interferons (IFNs) has been demonstrated in primary Sjögren's syndrome (pSS).[1-4] Type I IFNs are associated with higher disease activity and autoantibody levels.[5] Recent findings also show activation of interferon type II (IFN $\gamma$ ) induced gene expression in salivary glands of pSS patients.[6, 7] Although IFN type I and II bind to different receptors they induce partially overlapping gene expression patterns. Understanding the relative contribution of IFN type I and type II may deepen our knowledge in pSS pathogenesis and promote a stratified approach to therapeutic development.

Objectives: Determine IFN type I and II inducible gene expression in patients with pSS and correlate this to disease manifestations.

Methods: In whole blood of 50 pSS patients modular IFN scores were determined using real-time quantitative PCR followed by principal component analysis. Subsequently, five indicator genes per module were analysed in two independent European cohorts with a total of 141 patients.

Results: Three groups were distinguished: without IFN activation (19-47\%), with IFN type I (53-81\%) and with IFN type I+II activation (35-55\%). Patients with IFN activation (I or I+II) have a higher presence of auto-antibodies, IgG levels and lower lymphocyte counts compared to IFN negative patients. The biological domain of the EULAR Sjögren's Syndrome Disease Activity Index (biological-ESSDAI) was higher in patients with IFN activation, while total-ESSDAI scores were not significantly different.

$66-67 \%$ of the IFN type I positive patients had an additional IFN type II inducible gene expression. Patients with IFN type I+II activation have significantly higher IgG levels and lower lymphocyte counts compared to patients with only IFN type I activation. There were no differences in fatigue or dryness, but pain scores were lower.

Conclusions: pSS patients can be stratified according to their systemic IFN activation patterns. IFN activation $(I$ or $|+| l)$ is present in patients with the highest activity of the biological-ESSDAI. These data raise the possibility that the biological-ESSDAI rather than total-ESSDAI score may be a more sensitive endpoint for trials targeting either type I or type II IFN pathways.

References:

[1] Wildenberg, et al. EJI. 2008; 38(7):2024-2033.

[2] Gottenberg, et al. PNAS. 2006; 103(8):2770-2775.

[3] Hjelmervik, et al. A\&R. 2005; 52(5):1534-1544.

[4] Emamian, et al. Genes Immun. 2009; 10(4):285-296.

[5] Brkic, et al. ARD. 2013; 72(5):728-735.

[6] Hall, et al. PNAS. 2013; 72(5):728-735.

[7] Hall, et al. A\&R. 2012; 109(43):17609-17614.

Disclosure of Interest: None declared

DOI: 10.1136/annrheumdis-2017-eular.3688

\section{THURSDAY, 15 JUNE 2017}

\section{Progress in biological treatment of RA}

\section{OP0098 REMISSION AND MAINTENANCE OF EFFICACY IN A PHASE 2B STUDY OF VOBARILIZUMAB, AN ANTI-INTERLEUKIN 6 RECEPTOR NANOBODY, IN PATIENTS WITH MODERATE-TO-SEVERE RHEUMATOID ARTHRITIS DESPITE TREATMENT WITH METHOTREXATE}

T. Dörner ${ }^{1}$, M. Weinblatt ${ }^{2}$, P. Durez ${ }^{3}$, R. Alten ${ }^{4}$, K. Van Beneden ${ }^{5}$, E.J. Dombrecht ${ }^{5}$, K. De Beuf ${ }^{5}$, P. Schoen ${ }^{5}$, R.K. Zeldin ${ }^{5} .{ }^{1}$ Rheumatology and Clinical Immunology, Charité University Hospitals, Berlin, Germany; ${ }^{2}$ Division of Rheumatology, Immunology and Allergy, Brigham and Women's Hospital,
Boston, United States: ${ }^{3}$ Department Rheumatology, Cliniques Universitaires St-Luc, Sint-Lambrechts-Woluwe, Belgium; ${ }^{4}$ Schlosspark-Klinik, Berlin, Germany; ${ }^{5}$ Ablynx NV, Zwijnaarde, Belgium

Background: Vobarilizumab is a Nanobody ${ }^{\circledR}$ consisting of an anti-IL-6R domain and an anti-human serum albumin domain in development for treatment of RA. The efficacy and safety were assessed in a 24-week double-blind global phase $2 \mathrm{~b}$ study in patients with active RA on a stable background of MTX. Main efficacy and safety results were previously reported [1].

Objectives: To report the impact of treatment with vobarilizumab on secondary efficacy endpoints including SDAI and CDAI remission and the sustained response at 4 consecutive visits based on ACR50, ACR70 and DAS28CRP.

Methods: Patients were randomized to receive subcutaneously administered placebo or 1 of 4 dose regimens of vobarilizumab in addition to MTX. SDAI and CDAl remission at Week 24 was evaluated, as was maintenance of efficacy as defined by sustained DAS28 ${ }_{\text {CRP }}<2.6$ responses at 4 consecutive visits (i.e., at Weeks 12, 16, 20 and 24). In addition, a post-hoc analysis was performed on sustained ACR50 and ACR70 responses from Week 12 through Week 24. Proportions of patients achieving response for these endpoints were summarized by treatment group. Subjects with missing values were analyzed as non-responders.

Results: A total of 345 patients were randomized. Demographics and baseline characteristics were similar across groups with mean baseline DAS28 ${ }_{\mathrm{CRP}}$ between 5.8 and 6.2. At Week 24 , up to $19 \%$ and $20 \%$ in the vobarilizumab groups reached CDAI and SDAI remission, respectively vs. $10 \%$ and $9 \%$ who received placebo (Table 1).

Table 1. Percentage of patients with CDAI and SDAI remission at Week 24

\begin{tabular}{lccccc}
\hline & $\begin{array}{c}\text { Placebo } \\
(\mathrm{N}=69)\end{array}$ & $\begin{array}{c}\text { Vobarilizumab } \\
75 \mathrm{mg} \mathrm{q4w} \\
(\mathrm{N}=69)\end{array}$ & $\begin{array}{c}\text { Vobarilizumab } \\
150 \mathrm{mg} \mathrm{q4w} \\
(\mathrm{N}=70)\end{array}$ & $\begin{array}{c}\text { Vobarilizumab } \\
150 \mathrm{mg} q 2 \mathrm{w} \\
(\mathrm{N}=68)\end{array}$ & $\begin{array}{c}\text { Vobarilizumab } \\
225 \mathrm{mg} \mathrm{q2w} \\
(\mathrm{N}=69)\end{array}$ \\
\hline CDAI remission $(\leq 2.8)$ & 10 & 15 & 19 & 12 & 19 \\
SDAl remission $(\leq 3.3)$ & 9 & 10 & 19 & 15 & 20 \\
\hline
\end{tabular}

At Week 24 , up to $61 \%$ and $45 \%$ of the patients in the vobarilizumab groups achieved an ACR50 or ACR70 response, respectively ( $39 \%$ and $17 \%$ on placebo). Approximately one third of the randomized patients in the 3 highest treatment groups had a sustained ACR50 response from Week 12 through Week 24 (Table 2). Sustained remission defined by DAS2 $8_{\mathrm{CRP}}<2.6$ at 4 consecutive visits, i.e. at weeks $12,16,20$ and 24 , was observed in $20 \%$ to $25 \%$ of the patients in the 3 highest dosing arms compared with $3 \%$ of those receiving placebo.

Table 2. Percentage of patients with sustained efficacy response at 4 consecutive visits (Weeks $12,16,20$ and 24 )

\begin{tabular}{lccccc}
\hline & $\begin{array}{c}\text { Placebo } \\
(\mathrm{N}=69)\end{array}$ & $\begin{array}{c}\text { Vobarilizumab } \\
75 \mathrm{mg} \text { q4w } \\
(\mathrm{N}=69)\end{array}$ & $\begin{array}{c}\text { Vobarilizumab } \\
150 \mathrm{mg} \mathrm{q4w} \\
(\mathrm{N}=70)\end{array}$ & $\begin{array}{c}\text { Vobarilizumab } \\
150 \mathrm{mg} q 2 \mathrm{w} \\
(\mathrm{N}=68)\end{array}$ & $\begin{array}{c}\text { Vobarilizumab } \\
225 \mathrm{mg} \mathrm{q2w} \\
(\mathrm{N}=69)\end{array}$ \\
\hline DAS28 $\mathrm{CRP}<2.6$ & 3 & 4 & 20 & 25 & 20 \\
ACR50 & 16 & 14 & 29 & 31 & 39 \\
ACR70 & 4 & 7 & 11 & 13 & 13 \\
\hline
\end{tabular}

Conclusions: In patients with active RA, treatment with vobarilizumab at the 3 highest dose regimens in addition to MTX had a positive and sustained impact on disease activity through Week 24 as defined by clinically relevant efficacy endpoints.

References:

[1] Weinblatt et al. (Annual Scientific Meeting, Canadian Rheumatology Association, 2017).

Disclosure of Interest: T. Dörner Consultant for: Ablynx, M. Weinblatt Consultant for: Ablynx, P. Durez Consultant for: Ablynx, R. Alten Consultant for: Ablynx, K. Van Beneden Employee of: Ablynx, E. Dombrecht Employee of: Ablynx, K. De Beuf Employee of: Ablynx, P. Schoen Employee of: Ablynx, R. Zeldin Employee of: Ablynx

DOI: 10.1136/annrheumdis-2017-eular.3732

OP0099 SAFETY, TOLERABILITY AND INITIAL SIGNS OF EFFICACY OF THE FULLY HUMAN IMMUNOCYTOKINE DEKAVIL (F8IL10): A NOVEL THERAPEUTIC APPROACH FOR RHEUMATOID ARTHRITIS

M. Galeazzi ${ }^{1}$, G. Sebastiani ${ }^{2}$, R. Voll ${ }^{3}$, J. Wollenhaupt ${ }^{4}$, O. Viapiana ${ }^{5}$, J. Dudler ${ }^{6}$, E. Selvi ${ }^{1}$, C. Baldi ${ }^{1}$, M. Bardelli ${ }^{1}$, B. Bannert ${ }^{3}$, S. Finzel $^{3}$,

C. Specker ${ }^{7}$, P. Sarzi Puttini ${ }^{8}$, F. Bootz ${ }^{9}$, D. Neri ${ }^{10}$ on behalf of the DEKAVIL Study Group. ${ }^{1}$ University Hospital, Siena; ${ }^{2}$ San Camillo-Forlanini Hospital, Rome, Italy; ${ }^{3}$ University Medical Center, Freiburg; ${ }^{4}$ Schoen-Klinik, Hamburg Eilbek, Germany; ${ }^{5}$ University Hospital, Verona, Italy; ${ }^{6}$ Cantonal Hospital, Fribourg, Switzerland; ${ }^{7}$ University Hospital, Essen, Germany; ${ }^{8}$ Luigi Sacco Hospital, Milan, Italy; ${ }^{9}$ Philochem AG, Otelfingen, Switzerland; ${ }^{10}$ Philogen SpA, Siena, Italy

Background: The antibody-based targeted pharmacodelivery of cytokines by means of immunocytokines has the potential to enhance therapeutic activity at the site of disease while sparing healthy tissues. Dekavil (F8IL10) is a fully human immunocytokine composed of the vascular targeting antibody F8 (specific to 